\title{
The function of chaperone proteins in the assemblage of protein complexes involved in gamete adhesion and fusion processes
}

\author{
Elizabeth G Bromfield and Brett Nixon \\ Priority Research Centre in Reproductive Science, School of Environmental and Life Sciences, Discipline of Biological \\ Sciences, The University of Newcastle, Callaghan, New South Wales 2308, Australia \\ Correspondence should be addressed to B Nixon; Email: brett.nixon@newcastle.edu.au
}

\begin{abstract}
The remarkable complexity of the molecular events governing adhesion and fusion of the male and female gametes is becoming apparent. Novel research suggests that these highly specific cellular interactions are facilitated by multiprotein complexes that are delivered to and/or assembled on the surface of the gametes by molecular chaperones in preparation for sperm-egg interaction. While the activation of these molecular chaperones and the mechanisms by which they shuttle proteins to the surface of the cell remain the subject of ongoing investigation, a compelling suggestion is that these processes are augmented by dynamic membrane microdomains or lipid rafts that migrate to the apical region of the sperm head after capacitation. Preliminary studies of the oocyte plasma membrane have also revealed the presence of lipid rafts comprising several molecular chaperones, raising the possibility that similar mechanisms may be involved in the activation of maternal fusion machinery and the regulation of oocyte plasma membrane integrity. Despite these findings, the analysis of oocyte surface multiprotein complexes is currently lacking. Further analyses of the intermediary proteins that facilitate the expression of key players in sperm-egg fusion are likely to deliver important insights into this unique event, which culminates in the cytoplasmic continuity of the male and female gametes.
\end{abstract}

Reproduction (2013) 145 R31-R42

\section{Introduction}

Originally identified as inducible proteins involved in the protection of cells from multiple stresses, molecular chaperones are now recognized as participants in a diverse range of functions due to their ability to selectively bind to hydrophobic residues of target proteins, directing their involvement in correct protein folding or degradation pathways (Ellis 1987, Hendrick \& Hartl 1993). The heat shock proteins (HSPs), among other ubiquitous chaperone families, have well-documented roles in preventing the aberrant association or aggregation of proteins in addition to facilitating protein synthesis, translocation, de novo folding, and higher ordered assembly of multiprotein complexes (Hendrick \& Hartl 1993, Neuer et al. 2000). Among this multitude of functions, the ability of chaperones to mediate the assembly of oligomeric complexes is of particular interest as advances in functional proteomics have revealed that a significant portion of a cell's proteome realize their functional potential in multiprotein complexes rather than as singular entities (Sali et al. 2003).

This phenomenon is proving particularly true of the male gametes, which must complete several complex phases maturation in order to gain the functional competence to engage in one of the most intricate of all cellular interactions, fertilization. As transcriptionally inactive cells, spermatozoa rely heavily upon posttranslational modifications and remodeling of their constituent proteins to attain a state of functional maturity. For a sperm cell to interact with the oocyte, the activation of nascent, receptor-like proteins on the sperm surface is required, a process that has frequently been linked to the coordinated action of a subset of molecular chaperones (Ikawa et al. 2001, Asquith et al. 2004). Members of the HSP families, in addition to several other germ cell-specific chaperones, have been identified in both the mature spermatozoon of a number of species, including mouse (Asquith et al. 2004), human (Mitchell et al. 2007, Naaby-Hansen \& Herr 2010), and pig (Spinaci et al. 2005), and in mature murine (Calvert et al. 2003) and bovine (Kawarsky \& King 2001) oocytes and have been extensively implicated in gamete adhesion and fusion processes (Cayli et al. 2003, Asquith et al. 2004, Nixon et al. 2005, Huszar et al. 2007, Ikawa et al. 2011).

Preparation for oocyte interactions initially occurs through the formation of zona pellucida (ZP) binding sites during spermatogenesis (Huszar et al. 2007). Several molecular chaperones have been implicated in the remodeling of sperm membranes and the formation of oocyte binding domains during the production of 
morphologically mature cells in the testes (Ikawa et al. 1997, Huszar et al. 2000). Though this prepares the spermatozoon for fertilization, additional phases of post-testicular maturation must be completed to attain a state of functional maturity. These events are initiated during their transit of the epididymis, wherein spermatozoa are bathed in a dynamic luminal microenvironment (Robaire et al. 2006, Cornwall 2009). Within this milieu, the sperm plasma membrane experiences the loss, gain, and modification of multiple proteins, a process that results in the attainment of the potential to move progressively and engage in oocyte interactions (Hermo et al. 1991). As discussed in the following sections, emerging evidence has implicated several HSP family chaperones in these modifications of the sperm plasma membrane during epididymal maturation (Lachance et al. 2010, Naaby-Hansen et al. 2010).

As a culmination of both testicular and post-testicular maturation, spermatozoa are able to reach a capacitated state as they progress through the female reproductive tract en route to the site of fertilization. As they ascend the female reproductive tract, the composition of sperm membrane proteins and lipids is subject to further dramatic alterations (Yanagimachi 1994, Harrison et al. 1996, Gadella \& Harrison 2000, Gadella et al. 2008), resulting in the acquisition of the ability to recognize and bind to the outer vestments of the oocyte, the ZP. It is widely held that these binding events trigger acrosomal exocytosis and prime the cell for intercellular fusion with the oocyte. These collective events appear to be underpinned by a number of sperm surface protein complexes that comprise molecular chaperones, co-chaperones, and recognition proteins implicated in the specific interactions with oocyte ligands. Recently, a subset of these complexes has been demonstrated to undergo capacitation-associated assembly or activation (Asquith et al. 2005, Nixon et al. 2005). These chaperoneladen complexes may provide the basis for species-specific adhesion of spermatozoa to homologous oocytes and thus have been the major focus of studies of molecular chaperones in this field. In the ensuing review, we seek to discuss the role of molecular chaperones in the mediation of sperm-oocyte adhesion and fusion, two germ cellspecific events that are coordinated largely through the formation of multiprotein complexes.

\section{The role of chaperones in the acquisition of $\mathrm{ZP}$ binding potential}

Although the expression of chaperones is traditionally viewed as being induced by heat shock and other stresses, members of the HSP60, HSP70, and HSP90 families have proven to be abundant components of the sperm surface that are constitutively expressed in the male germline and function as critical mediators of protein maturation during spermatogenesis (Miller et al. 1992, Boulanger et al. 1995). The generation of a mature spermatozoon requires multiple maturation steps; the first of these occurs in the testis and is assisted by the regulatory action of a diverse family of chaperones, including chaperonincontaining T-complex/TCP1-ring complex (CCT/TRiC), HSP60 (or HSPD1; Meinhardt et al. 1995), clusterin (Onoda \& Djakiew 1990), HSPA2 (Huszar et al. 2000), and the testis-specific chaperones calmegin (CLGN; Ikawa et al. 1997, Ohsako et al. 1994), and calsperin (CALR3; Ikawa et al. 2011), which are developmentally regulated and expressed in spermatogenic cells (see also Dun et al. (2012a)).

The role of these chaperones extends to arguably the most essential step in the acquisition of sperm fertilizing potential during spermatogenesis, the remodeling of the sperm morphology through the extrusion of excess cytoplasm, and the formation of a number of highly specialized domains. This remodeling phase culminates in the formation of both hyaluronic acid and ZP binding sites on the sperm plasma membrane that are fundamental to the processes of cumulus oophorus penetration and ZP interaction (Huszar et al. 2000, 2007). Little is known regarding the mechanisms that underpin ZP binding site formation; however, in immature human sperm, the presence of a low number of zona binding sites and hyaluronic acid receptor sites as well as a corresponding reduction in fertility potential has been causally related to the reduced expression of the $70 \mathrm{kDa}$ testis-expressed chaperone, HSPA2 (Huszar et al. 2000, Celik-Ozenci et al. 2003).

In the human, HSPA2 is expressed in the synaptonemal complex of spermatocytes and is again synthesized during late spermiogenesis concurrently with cytoplasmic extrusion and sperm plasma membrane remodeling, processes that require major sperm protein translocations (Huszar et al. 2000). In concert with a number of other testis-expressed chaperones (see below), HSPA2 assists in the mediation of correct protein folding and translocation to appropriate subcellular domains to produce a morphologically mature spermatozoon (Huszar et al. 2000, 2003). The importance of HSPA2 in spermatogenic differentiation is reinforced by studies that indicate that the diminished expression of this chaperone is associated with apoptosis (Dix et al. 1996, Nasr-Esfahani et al. 2010), DNA fragmentation (Kovanci et al. 2001), a lack of histone-protamine substitution (Nasr-Esfahani et al. 2001), increased levels of lipid peroxidation (Huszar et al. 2000), increased frequency of chromosomal aneuploidies (Nasr-Esfahani et al. 2001), as well as IVF failure (Huszar et al. 1992, 2003). Indeed, in the mouse, the targeted elimination of HSPA2 leads to a complete arrest of spermatogenesis (Allen et al. 1996, Mori et al. 1997). These defects appear to be a result of misfolding, misexpression, or incorrect processing of proteins during spermatogenesis (Neuer et al. 2000). 
In some instances, chaperones, such as the testisspecific calmegin, remain imperative to sperm function despite the fact that they are not expressed in the mature cell. Such chaperones are necessary as they ensure correct folding of endoplasmic reticulum glycoproteins that are destined to play a more direct role in zona adhesion in addition to promoting their delivery to the appropriate plasma membrane domain (lkawa et al. 1997). Indeed, disruption of the calmegin (lkawa et al. 1997, Ikawa et al. 2001) and calsperin (Ikawa et al. 2011) genes in mice has been demonstrated to compromise male fertility due to the impaired formation of testis-specific t-fertilin (ADAM1A and ADAM2, where ADAM denotes a disintegrin and metalloprotease) and sperm surface s-fertilin (ADAM1B and ADAM2) complexes. Such defects are causally associated with impaired zona binding and reduced sperm transport through the uterotubal junction of the female reproductive tract (Ikawa et al. 2001). Interestingly, this phenotype is shared among several knockout models, including calmegin, calsperin, ADAM1A, and ADAM2, and appears to be attributed to the absence of ADAM3 from spermatozoa in each instance (Yamaguchi et al. 2006). Such a finding suggests that the assembly of the fertilin complexes by chaperones during spermatogenesis is essential for the formation of ZP recognition domains as well as the processing and/or escort of key receptor proteins such as ADAM3 (Muro \& Okabe 2011).

Following their release from the testes, the second major phase of sperm maturation occurs as the cells progress through the dynamic environment of the epididymis, the extratesticular duct that connects the testis and the vas deferens. As a culmination of epididymal maturation, spermatozoa acquire the potential to move progressively and interact with the ZP. Chaperone proteins including clusterin (Hermo et al. 1991), HSPA5 (Lachance et al. 2010, Naaby-Hansen et al. 2010), and HSPD1 (Asquith et al. 2005) are thought to regulate epididymal maturation through their indirect roles in promoting the remodeling of sperm surface architecture (Dun et al. 2012a). Although the mechanisms by which proteins are incorporated into spermatozoa during epididymal maturation are yet to be completely resolved, it is postulated that this process occurs through sperm membrane fusion with small, epididymal exosomal vesicles termed epididymosomes (Frenette \& Sullivan 2001, Sullivan et al. 2007) and/or amorphous, electron-dense structures termed dense bodies (Asquith et al. 2005). The expression of several molecular chaperones in epididymosomes (Frenette \& Sullivan 2001, Saez et al. 2003, Sullivan et al. 2005) and dense bodies, including HSPD1, suggests that these proteins may facilitate the bulk transfer of new protein onto the sperm surface during epididymal maturation (Asquith et al. 2005, Dun et al. 2011). In addition, there is some evidence to suggest a correlation between the presence of clusterin-positive sperm and bull fertility (Ibrahim et al. 2000).

In mature mouse sperm, HSPD1 has been shown to subsequently interact with additional chaperones HSPE1 and CCT/TRiC as well as a putative ZP receptor candidate ADAMTS10 (Walsh et al. 2008, Dun et al. 2011, 2012b), which exemplifies the important role this chaperone may play in epididymal sperm surface remodeling to prepare the cell for ZP interactions. In support of this model, HSPA5 has also been identified in epididymosomes (Lachance et al. 2010) and together with its putative client protein, ADAM7, is also transferred to the sperm surface during epididymal maturation (Oh et al. 2009). Within spermatozoa, these proteins form a multimeric complex (comprising an additional chaperone, calnexin, and integral membrane protein $2 \mathrm{~B}$ ), which has been implicated in spermoocyte interactions (Han et al. 2011). These findings draw interesting analogies with a number of other cell types, including that of metastatic cancers, where chaperones have been intimately tied to the function of metalloproteases, raising the possibility that this form of interaction may regulate a range of biological and pathological processes (Ikawa et al. 2010).

Despite the collective importance of these maturation stages in the acquisition of ZP binding potential, they do not represent the final changes necessary for the spermatozoon to engage in fertilization. Rather, a further pivotal maturation phase must take place postejaculation within the female reproductive tract.

\section{Multiprotein complexes in sperm capacitation and ZP interaction}

Upon reaching the site of fertilization, the ampulla, spermatozoa must penetrate two barriers before fusing with the oocyte plasma membrane, or oolemma. The first of these is a hyaluronic acid-rich stratum of cumulus cells that surround the oocyte and the second is the extracellular matrix of the oocyte itself, the ZP (Hartmann et al. 1972). Despite the development of both ZP and hyaluronic acid binding sites during spermatogenesis and the acquisition of binding potential as spermatozoa transit the epididymis, these cells require a distinct period of residence within the female reproductive tract before they are able to successfully partake in such interactions (Austin 1951, Chang 1951). The collective changes that spermatozoa undergo within this environment, termed capacitation, enable the cells to respond to signals arising from the cumulus oocyte complex and complete a process of acrosomal exocytosis, rendering them competent for fusion with the oolemma.

The ZP is comprised of a suite of sulfoglycoproteins, namely ZP1, ZP2 and ZP3, that are highly conserved in most mammalian species (though an additional ligand, ZP4/B, has been reported in human and pig oocytes) 
(Wassarman et al. 1999, Lefievre et al. 2002, Yonezawa et al. 2012). It is generally held that these ligands govern sperm binding in most species (see also Reid et al. (2011)). Remarkably, however, various models are currently still under consideration regarding the identity of the primary sperm receptor within the ZP and the mechanisms by which spermatozoa adhere to this matrix (see also Visconti \& Florman (2010)). Similarly, investigations into the identity of the corresponding sperm surface receptor(s) that recognize the appropriate ligand(s) on the ZP have also failed to provide definitive answers. Indeed, there is a growing literature of murine knockouts of auspicious receptor protein candidates (including $\beta$-1,4-galactosyltransferase (GALT1), arylsulfatase A (ARSA), and sperm adhesion molecule 1 (SPAM1); for a complete list, see Ikawa et al. (2010)) that each fail to result in complete infertility (Hess et al. 1996, Asano et al. 1997, Baba et al. 2002). Rather, various degrees of reduced binding capability are exhibited, raising the possibility that this process encompasses a degree of functional redundancy and that a number of sperm proteins act in concert to mediate ZP adhesion. The coordination of the activity of these proteins to ensure productive ZP interactions is thus emerging as an important research focus.

In most eutherian mammals, sperm capacitation is thought to be initiated by the activation of a cAMPmediated pathway that culminates in the tyrosine phosphorylation of multiple sperm proteins (Visconti et al. 1995a, 1995b, Leclerc et al. 1996). Molecular chaperones feature prominently among this suite of proteins, with HSP90AA1, HSP90B1 and HSPD1 being among the proteins revealed to display tyrosine phosphorylation as a consequence of capacitation (Ecroyd et al. 2003, Asquith et al. 2004). Current models suggest that the phosphorylation of these chaperones during capacitation triggers their active role in the assembly of ZP recognition proteins into complexes and/or the translocation of these complexes to the surface of spermatozoa in preparation for fertilization (Ecroyd et al. 2003, Asquith et al. 2004, Nixon et al. 2005, Gadella 2008). Further to this indirect role in gamete adhesion, sperm surface chaperones also have purported functions as adhesion molecules that mediate the recognition of sulfoglycolipids during gamete binding (Boulanger et al. 1995, Mamelak \& Lingwood 2001).

Recently, the technique of blue native PAGE (BNPAGE), which was originally developed for the analysis of electron transport chain multienzyme complexes (Schägger \& von Jagow 1991, Schägger et al. 1994), has been adapted for the assessment of multimeric sperm surface complexes in mice and humans (Dun et al. 2011, Redgrove et al. 2011). This technique allows for the electrophoretic resolution of native protein complexes that retain their biological activity. In human and mouse spermatozoa, the use of BN-PAGE in parallel with Far-Western blotting with whole solubilized zonae has revealed several primary multiprotein complexes that possess affinity for homologous ZP (Dun et al. 2011, Redgrove et al. 2011).

One such complex has been reported to comprise the protein components of the CCT/TRiC complex (CCT1-CCT8), a double-ring structure that functions as a molecular chaperone with a key role in regulating the formation of multiprotein complexes (Feldman et al. 1999, Guenther et al. 2002). Putative evidence in the form of co-immunoprecipitation, co-localization, and proximity ligation assays has identified ZP binding protein 2 (ZPBP2) as one of the most compelling client proteins for the CCT/TRiC complex in mature spermatozoa (Dun et al. 2011, Redgrove et al. 2011). Originally implicated in secondary ZP binding, a more recent study has shown that male mice null for ZPBP2 are subfertile and display defects in ZP interaction and penetration (Lin et al. 2007). In mice, there is additional evidence that certain CCT/TRiC complex subunits are translocated to the sperm surface during sperm capacitation (Dun et al. 2011).

Another prominent class of chaperones that has been identified on the sperm surface and implicated in the regulation of ZP interactions is the HSP70 family (Naaby-Hansen et al. 2010). As with the CCT/TRiC complex, HSP70 family chaperones also have welldocumented roles in the facilitation of both transmembrane protein transport and assembly of stable protein complexes (Mayer \& Bukau 2005). One member of the HSP70 family that displays exclusive (mouse) or predominant (human) expression in the testes appears to be essential for male fertility. Indeed, aberrant expression of this chaperone, HSPA2, has been correlated with a phenotype of severe male factor infertility in humans, specifically affecting the ability of spermatozoa to interact with homologous oocytes in vitro (Eddy 1999, Huszar et al. 2007). In both mice and humans, HSPA2 has a fundamental role in spermatogenesis, with targeted deletion of the protein in the former species leading to an early arrest of this process and a concomitant absence of spermatozoa (Eddy 1999). In humans, the expression levels of HSPA2 have been positively correlated with the success of fertilization in vitro (Huszar et al. 2000, 2006, Cayli et al. 2003) and hence are purportedly able to predict the fertility status of men with a high degree of accuracy (Ergur et al. 2002).

Characterization of HSPA2 in our own laboratory has revealed that this chaperone is present in the acrosomal domain of human spermatozoa and is a component of at least five high-molecular-mass protein complexes (Redgrove et al. 2012), including a subset of those shown previously to possess ZP affinity (Redgrove et al. 2011). Consistent with these data, we have secured evidence that the most dominant of the HSPA2 complexes contains two additional proteins, both of which have been previously implicated in sperm-zona interactions (Redgrove et al. 2012). Furthermore, in agreement with 
the published results of Huszar et al., we have been able to demonstrate a significant reduction in HSPA2 levels in the spermatozoa of men with isolated lesions in their ability to engage in interactions with ZP of homologous oocytes in vitro (Redgrove et al. 2012). Our current work is focusing on whether the deficit in ZP adhesion either results from aberrant formation of ZP binding sites in the early stages of spermiogenesis (Huszar et al. 2000) or may be the result of the inability of HSPA2 to participate in sperm surface remodeling events during capacitation such as facilitating the assembly and/or presentation of $Z \mathrm{P}$ receptors on the sperm surface in preparation for ZP interaction.

In addition to our own work on the assembly of sperm surface complexes, Han et al. have independently identified an alternative chaperone-laden multiprotein complex on the surface of mouse spermatozoa. Interestingly, as documented above, this complex, comprising HSPA5, calnexin, integral membrane protein $2 \mathrm{~B}$, and ADAM7, is apparently assembled during capacitation (Han et al. 2011). While the function of this complex has yet to be fully elucidated, the expression of ADAM7 has been linked to the presence of additional ADAM proteins, ADAM2 and ADAM3 (Kim et al. 2006), that are important for adhesion of spermatozoa to the ZP (Muro \& Okabe 2011). In addition, it is known that HSPA5 is involved in promoting adhesion of high-quality spermatozoa to oviductal epithelial cells (OEC) in the isthmus of the female reproductive tract. The formation of this reservoir is believed to have pro-survival effects in terms of maintaining sperm in a non-capacitated, quiescent state in preparation for the oocyte to be released to the ampulla (Topfer-Petersen et al. 2002). Interestingly, the chaperones HSPD1 and HSPA5 have also been localized to the surface of bovine OEC and have thus been implicated in sperm-OEC binding (Boilard et al. 2004).

Also consistent with our own work, the complex identified by Han et al. was shown to reside in membrane microdomains or lipid rafts, specialized regions of the membrane that provide a platform for the functional assembly and presentation of multiprotein complexes (Stein et al. 2006, Nixon et al. 2009, Han et al. 2011). The partitioning of chaperone complexes into the raft environment has also been observed for HSPA2 in human spermatozoa (Nixon et al. 2011) and for components of the CCT/TRiC complex in mouse spermatozoa (Dun et al. 2011). These membrane domains also comprise a number of additional putative ZP receptor proteins, including GALT1, ZP3R, and SPAM1, reinforcing their role in the remodeling of the sperm surface and in ZP binding (Fig. 1; Nixon et al. 2009, Asano et al. 2010). The mechanism(s) by which such proteins are recruited to the lipid rafts are yet to be resolved; however, HSPA2 has been reported to bind via its ATPase domain to 3'sulfogalactosylglycerolipid, the major glycoprotein identified within sperm lipid rafts (Mamelak \& Lingwood 2001).

In addition to the putative role of lipid rafts in repositioning of key chaperone complexes and ZP receptor proteins, there is also compelling evidence that many putative ZP receptors, such as ARSA and ZP3R, as well as several molecular chaperones show a capacitation-dependent relocation from intracellular sites such as the acrosome to the sperm surface to prime the cells in advance of their interactions with the ZP (Nixon et al. 2009). It has been proposed that intimate contact between the outer acrosomal membrane and the sperm plasma membrane is mediated through the binding of complementary soluble $\mathrm{N}$-ethylmaleimidesensitive factor attachment protein receptor (SNARE) proteins, leading to the formation of fusion pores that provide a route for the migration of enzymes to the sperm surface before the complete loss of the acrosomal contents (Søgaard et al. 1994, Blas et al. 2005, Tsai et al. 2007). In support of this model, a study by Brahmaraju et al. (2004) demonstrated that administration of antibodies to VAMP and SNAP into the acrosomal vesicle inhibited sperm-ZP binding in the mouse.

This progressive priming of the sperm surface has raised questions regarding the all or none nature of acrosomal exocytosis. Nevertheless, the functional assembly of SNARE complexes also appears to underpin the prolonged sperm membrane fusion events that permit a complete loss of the acrosomal contents (Tsai et al. 2010). Though it is widely held that contact with the ZP initiates this acrosomal exocytosis in most mammalian species, a number of studies performed in the mouse have demonstrated that spermatozoa that begin acrosomal exocytosis before contact with the ZP are still able to fertilize the oocyte (Nakanishi et al. 1999, Jin et al. 2011). This phenomenon may also be true of guinea pig (Huang et al. 1981) and hamster spermatozoa (Yanagimachi \& Phillips 1984). Such findings suggest an important role for the cumulus oophorus in the initiation of the acrosome reaction and raise concerns regarding the ability of in vitro studies performed with cumulusdenuded oocyte zona structures to accurately report on the true nature of the acrosome reaction and indeed ZP interaction.

Notwithstanding such controversy, chaperone-like molecules have also been implicated in acrosomal exocytosis by virtue of their ability to promote the assembly of glutamine-containing SNAREs (Q-SNAREs) and arginine-containing SNARES (T-SNAREs) into tight ternary complexes (Tomes et al. 2002, Sørensen 2005). Interestingly, elegant studies in pigs have demonstrated that capacitation induces stable docking of the sperm plasma membrane with the outer acrosomal membrane in preparation for fertilization (Tsai et al. 2010). More recent studies performed by Tsai et al. (2012) have also provided evidence for the presence of unilamellar mixed vesicles that, among other important functions, allow the 


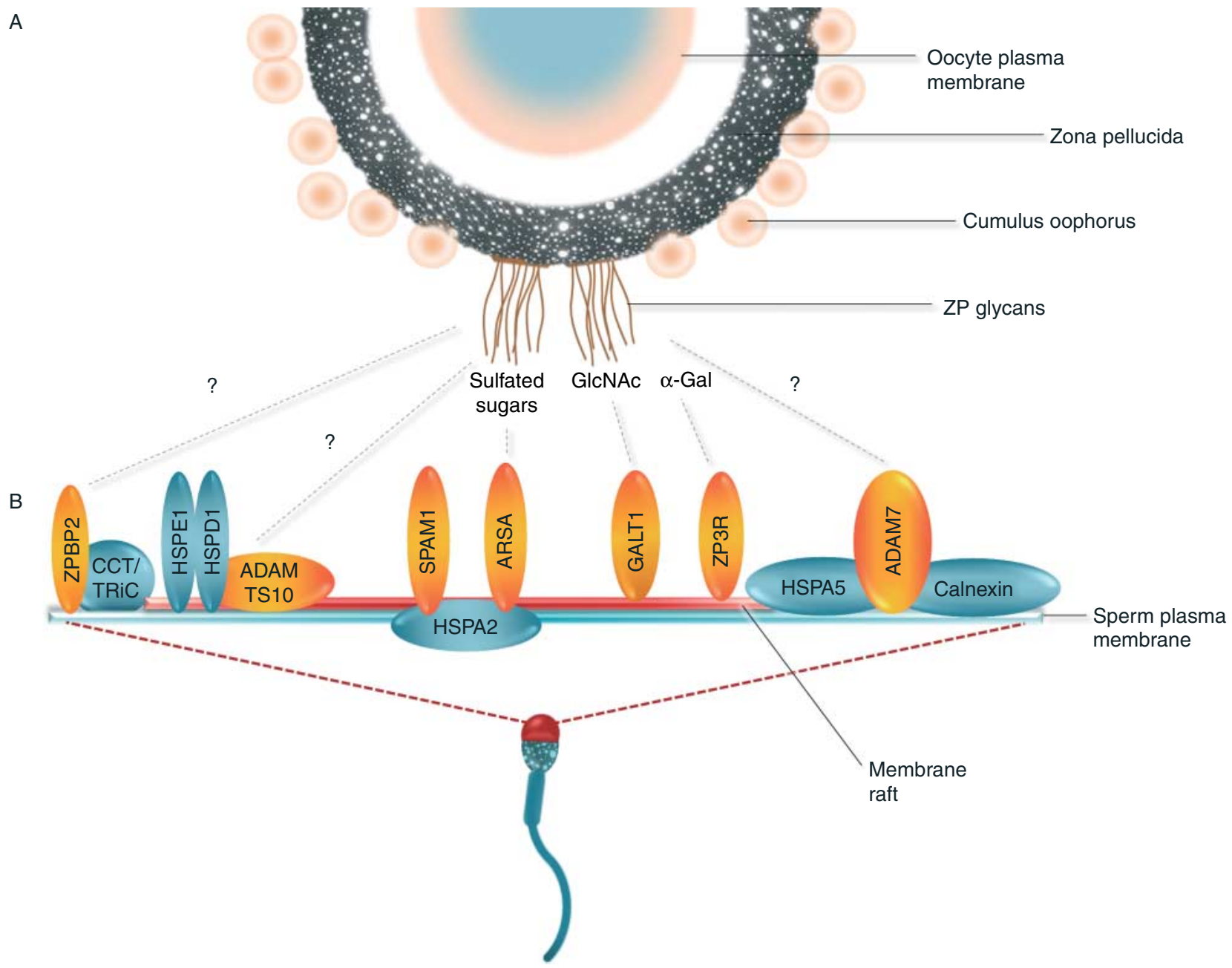

Figure 1 The mammalian oocyte and its complementary receptors and chaperones on the sperm surface. (A) The balance of evidence suggests that the mammalian oocyte selectively interacts with the spermatozoon through glycans conjugated to ZP3 and/or elements of the ZP2 and ZP3 peptide backbones. (B) While the identity of the complementary sperm receptors has yet to be fully elucidated, it is known that spermatozoa possess membrane rafts that undergo a capacitation-dependent reorganization to become confined within the apical region of the sperm head. These membrane domains have been shown to contain a number of putative ZP receptor proteins (orange), including SPAM1, ARSA, GALT1, and ZP3R, as well as several molecular chaperones (blue) such as CCT/TRiC, HSPA2, HSPD1, and HSPE1. On the basis of this evidence, it has been proposed that membrane rafts serve as a platform for the chaperone-mediated assembly of functional oocyte-receptor complexes on the sperm surface. Among these putative complexes that have been identified to date are those that comprise CCT/TRiC/ZPBP2, HSPD1/HSPE1/ADAMTS10, HSPA2/ARSA/SPAM1, and HSPA5/ADAM7/calnexin. Though we have much to learn regarding the specific interactions between sperm surface receptors, chaperones, and ZP ligands, some examples of proposed interactions include ARSA interaction with sulfated ZP2/ZP3 glycans via a positively charged active site pocket; GALT1, a carbohydrate binding protein that specifically recognizes terminal $N$-acetylglucosamine (GlcNAc) sugar residues on ZP3; and ZP3R, a member of the superfamily of C3/C4 binding proteins that interacts with terminal $\alpha$-galactose ( $\alpha$-Gal) residues on ZP3. Such a large number of putative sperm-ZP receptors suggest that a high level of functional redundancy is associated with this critical aspect of the fertilization cascade.

recruitment of secondary ZP binding proteins at the sperm surface and possess a novel trimeric SNARE complex consisting of syntaxin 3, SNAP23, VAMP2, and an additional protein, complexin 2. The energy released by the formation of such complexes is in turn used to initiate membrane fusion by pulling together the plasma membrane and inner acrosomal membrane of the spermatozoon (Tomes et al. 2002). The completion of this process is critical in the exposure of sperm domains that participate in the downstream events of fertilization: oolemma binding and fusion.

\section{Molecular chaperones in gamete fusion}

Sperm-oocyte fusion occurs between the inner acrosomal membrane of the sperm cell and the microvillar-rich region of the oocyte plasma membrane (Johnson et al. 1975). Specific fusion proteins tightly regulate these events through interactions with lipids and other protein ligands. Through comprehensively studied membrane fusion processes such as vesicle trafficking and viruscell fusion, it has been revealed that membrane fusion often involves an initial tethering step, followed by the 
activation of the fusion machinery, the close apposition of the lipid bilayers, and then the final fusion of the membranes (Jahn \& Grubmüller 2002).

Although evidence for the role of chaperones in the mediation of intercellular gamete fusion is limited, given the mounting support for the involvement of chaperoneladen complexes in the regulation of ZP binding, it is expected that this ubiquitous class of proteins may also assist in the activation of fusion machinery and/or organization of functional fusion complexes. Analogous to the regulation of sperm-ZP interaction, a functional redundancy exists between the numerous sperm proteins required for efficient fusion of the sperm cell to the oolemma. One sperm protein that has been established as essential for sperm-oocyte fusion is IZUMO1. IZUMO1 was originally identified in spermatozoa through the use of anti-sperm monoclonal antibodies that were shown to block IVF and, upon being knocked out, Izumo1-null sperm were shown to be unable to fuse with the oolemma (Inoue et al. 2005).

Notwithstanding recent evidence from knockout models, an extensive body of literature suggests that ADAMs are also vital for sperm-egg adhesion and fusion (Primakoff et al. 1987, Cho et al. 1998, Nishimura et al. 2001, Choi et al. 2003). ADAMs share adhesionmediating motifs that allow them to interact with integrins on the egg surface. However, this interaction occurs in a coordinated manner, possibly with IZUMO1 and the fusogen, angiotensin-converting enzyme 3 (ACE3; Krege et al. 1995), and as such no ADAM has thus far been found to be singularly essential for spermegg interaction. Preliminary evidence of the interaction between IZUMO1, ACE3, and the ADAM family of proteins was afforded by Ellerman et al. (2009) who indicated that ACE3 and ADAM proteins possess an Izumo domain and are able to form heteromultimeric complexes on spermatozoa. Given that ADAMs are able to form heteromultimeric complexes and have been shown to interact with several molecular chaperones during the maturation events upstream of fusion, it is tempting to speculate that molecular chaperones may coordinate the actions of ADAMs during fusion; however, such a role is yet to be investigated.

In terms of the maternal contributions to membrane fusion, egg plasma membrane tetraspanins and integrin receptors are the key molecules to have been implicated in sperm adhesion and fusion processes. Of particular importance are CD9 and CD81, members of the tetraspanin family that are present on the oolemma and essential for sperm-egg fusion (Kaji et al. 2000, Le Naour et al. 2000, Miyado et al. 2000). Remarkably, CD9 and CD81 appear to work in concert to facilitate fusion and when knocked out simultaneously, $C d 9^{-1-} / C d 81^{-1-}$ females are completely infertile (Rubinstein et al. 2006). Though the precise role of these tetraspanins is unclear (for a current review, see Evans (2012)), CD9 has interestingly been reported to contribute to fusion through the organization of functional oolemmal multimeric complexes (Chen et al. 1999).

Although a link between oocyte tetraspanins and the action of molecular chaperones has not been developed, tetraspanins have been shown to interact with chaperones in other cell types. Working in a B-cell model, it has been shown that the chaperone, calnexin, and the tetraspanins, CD9 (Rubinstein et al. 1997) and CD82 (Cannon \& Cresswell 2001), can be coimmunoprecipitated from this cell type. Additionally, the endoplasmic reticulum transmembrane domain chaperone BAP31 has been identified as a constituent of a high-molecular-weight complex in which it associates with the integrin $\mathrm{CD} 11 \mathrm{c} / \mathrm{CD} 18$, regulating the mobilization of the integrin complex to the neutrophil cell surface from secondary granules (Zen et al. 2009). This activity may be mediated through the chaperones' association with hydrophilic residues of the transmembrane domains of its client proteins (Adachi et al. 1996). In turn, BAP31 has also been shown to form complexes with calnexin (Zuppini et al. 2002) and is thought to regulate tetraspanin trafficking through the assembly of tetraspanin-calnexin complexes (Berditchevski \& Odintsova 2007).

The presence of multiprotein complexes on the surface of the oocyte has not been extensively investigated due to the difficulty in acquiring significant biological material to characterize the proteome or perform analyses such as BN-PAGE. Despite this, the individual chaperone proteins, calreticulin, calnexin, HSPA1A, HSPA5, HSP90AA1, and HSP90B1, have been confirmed on the surface of mature mouse oocytes (Calvert et al. 2003) and may act in a coordinated manner to activate fusion machinery on the surface of the oocyte. In an independent study, calreticulin has also been found to localize to the cortical granules of hamster oocytes and appears to be released into the perivitelline space following oocyte activation (MunozGotera et al. 2001), raising the possibility that it is involved in the priming of oocytes in preparation for fusion with a spermatozoon.

Of the chaperone proteins identified on the oolemma, HSP70 is constitutively synthesized in the preovulatory mouse oocyte (Calvert et al. 2003) as well as the mature bovine oocyte (Kawarsky \& King 2001). Following zygotic gene activation in the two-cell mouse embryo, HSP70 is one of the primary genes to be expressed. From this observation, it is anticipated that chaperones of the HSP family that are found in the mature egg may be required to ensure accurate translation and folding of nascent proteins during activation of the zygotic genome. Furthermore, HSP70 and an additional chaperone protein, HSPA5, possess anti-apoptotic activity that may imply that HSPs have uncharacterized functions in terms of promoting cell survival (Heikkila et al. 1986). 


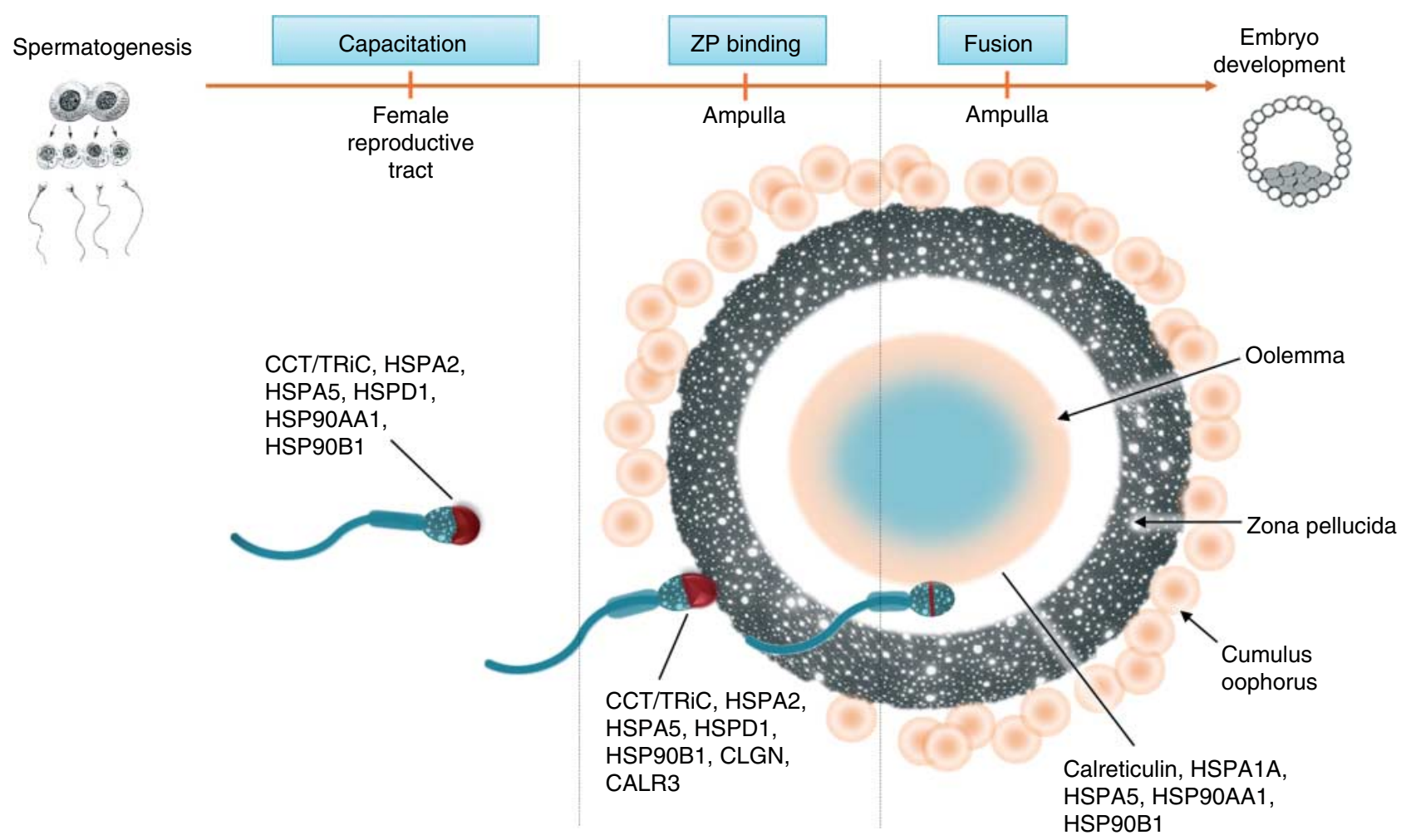

Figure 2 Chaperone expression during capacitation, ZP interaction, and sperm-oolemma fusion. A large suite of molecular chaperones have been implicated in the structural and functional maturation of mammalian spermatozoa within the testes and male reproductive tract. The presence of a number of these chaperones in ejaculated spermatozoa raises the possibility that they fulfill important functions during the capacitation of these cells and in facilitating their interaction with the oocyte within the ampulla of the female reproductive tract. Consistent with this notion, molecular chaperones including CCT/TRiC, HSPA2, HSPA5, HSPD1, HSP90AA1, and HSP90B1 have been shown to be targets for capacitation-associated modification and/or have been indirectly implicated in zona recognition. Specifically, chaperones such as these appear to assist in priming the sperm surface architecture for ZP interactions by virtue of their ability to assemble/present and/or activate ZP-receptor complexes. Although the role of chaperones in downstream interactions such as adhesion and fusion to the oolemma is less certain, a number of them including calreticulin, HSPA1A, HSPA5, HSP90AA1, and HSP90B1 have been localized to the surface of the oolemma and are thus well positioned to participate in these processes.

\section{Conclusions}

Though it is widely accepted that molecular chaperones are vital for the maturation of mammalian spermatozoa in the testis and epididymis, techniques such as BN-PAGE have led to the discovery of functional, chaperone-laden complexes in the mature sperm cell. In addition, murine gene manipulation studies and bioassays have begun to elucidate the functional roles of these chaperones in gamete interactions. Such studies have established a link between the phosphorylation of molecular chaperones during sperm capacitation and the formation and/or presentation of multiprotein complexes on the surface of the cell. Many of these complexes comprise putative ZP receptor proteins, and accordingly, they have been shown to possess affinity for homologous zonae. The presence of multiple chaperone-laden, ZP recognition complexes on the surface of the spermatozoon at the time of fertilization is consistent with the high level of functional redundancy that characterizes this intricate adhesion event.
Downstream of ZP interactions, little is known regarding the role of chaperones in the activation of fusion machinery and the subsequent adhesion and fusion of a spermatozoon to the oolemma. It is of interest, however, that several chaperone proteins have been identified on the surface of the oocyte. This discovery raises the possibility that chaperones mediate the formation of multiprotein complexes on the female gamete that may assist in fusion and could represent a maternal selection of essential protein folding machinery. Given the similar number of gamete fusion candidates to those involved in sperm-ZP binding, it is highly likely that multiple proteins regulate this process through the formation of functional complexes. Whether molecular chaperones are essential for the coordination of such complexes is yet to be determined and is a focus for future research into the elucidation of gamete interactions in our laboratory.

In summary, the key roles attributed to chaperone expression during capacitation, ZP interaction, and 
sperm-oolemma fusion (Fig. 2) highlight the importance of the chaperone machinery in gamete biology and may set the stage for an exciting new facet of proteomic research.

\section{Declaration of interest}

The authors declare that there is no conflict of interest that could be perceived as prejudicing the impartiality of the research reported in this review.

\section{Funding}

The authors gratefully acknowledge the financial assistance to B Nixon by the Australian Research Council, National Health and Medical Research Council, and the University of Newcastle. E G Bromfield is the recipient of an Australian Postgraduate Award PhD scholarship.

\section{Acknowledgements}

The authors would like to thank Dr Kate Redgrove for her contributions to this article.

\section{References}

Adachi T, Schamel WW, Kim KM, Watanabe T, Becker B, Nielsen PJ \& Reth M 1996 The specificity of association of the IgD molecule with the accesory proteins BAP31/BAP29 lies in the IgD transmembrane sequence. EMBO Journal 15 1534-1541.

Allen JW, Dix DJ, Collins BW, Merrick BA, He C, Selkirk JK, PoormanAllen P, Dresser ME \& Eddy EM 1996 HSP70-2 is part of the synaptonemal complex in mouse and hamster spermatocytes. Chromosoma 104 414-421. (doi:10.1007/BF00352265)

Asano M, Furukawa K, Kido M, Matsumoto S, Umesaki Y, Kochibe N \& Iwakura Y 1997 Growth retardation and early death of $\beta-1$, 4-galactosyltransferase knockout mice with augmented proliferation and abnormal differentiation of epithelial cells. EMBO Journal $\mathbf{1 6}$ 1850-1857. (doi:10.1093/emboj/16.8.1850)

Asano A, Nelson JL, Zhang S \& Travis AJ 2010 Characterization of the proteomes associating with three distinct membrane raft sub-types in murine sperm. Proteomics 10 3494-3505. (doi:10.1002/pmic.2010 00002)

Asquith KL, Baleato RM, McLaughlin EA, Nixon B \& Aitken RJ 2004 Tyrosine phosphorylation activates surface chaperones facilitating sperm-zona recognition. Journal of Cell Science 117 3645-3657. (doi:10.1242/jcs.01214)

Asquith KL, Harman AJ, McLaughlin EA, Nixon B \& Aitken RJ 2005 Localization and significance of molecular chaperones, heat shock protein 1, and tumor rejection antigen gp96 in the male reproductive tract and during capacitation and acrosome reaction. Biology of Reproduction 72 328-337. (doi:10.1095/biolreprod.104.034470)

Austin CR 1951 Observation on the penetration of sperm into the mammalian egg. Australian Journal of Scientific Research. Series B: Biological Sciences B4 697-698.

Baba D, Kashiwabara S-I, Honda A, Yamagata K, Wu Q, Ikawa M, Okabe M \& Baba T 2002 Mouse sperm lacking cell surface hyaluronidase PH-20 can pass through the layer of cumulus cells and fertilize the egg. Journal of Biological Chemistry 277 30310-30314. (doi:10.1074/jbc. M204596200)

Berditchevski F \& Odintsova E 2007 Tetraspanins as regulators of protein trafficking. Traffic 8 89-96. (doi:10.1111/j.1600-0854.2006.00515.x)

Blas GAD, Roggero CM, Tomes CN \& Mayorga LS 2005 Dynamics of SNARE assembly and disassembly during sperm acrosomal exocytosis. PLoS Biology 3 e323. (doi:10.1371/journal.pbio.0030323)
Boilard M, Reyes-Moreno C, Lachance C, Massicotte L, Bailey JL, Sirard MA \& Leclerc P 2004 Localization of the chaperone proteins GRP78 and HSP60 on the luminal surface of bovine oviduct epithelial cells and their association with spermatozoa. Biology of Reproduction 71 1879-1889. (doi:10.1095/biolreprod.103.026849)

Boulanger J, Faulds D, Eddy EM \& Lingwood CA 1995 Members of the 70 $\mathrm{kDa}$ heat shock protein family specifically recognize sulfoglycolipids: role in gamete recognition and mycoplasma-related infertility. Journal of Cellular Physiology 165 7-17. (doi:10.1002/jcp.1041650103)

Brahmaraju M, Shoeb M, Laloraya M \& Kumar PG 2004 Spatio-temporal organization of Vam6P and SNAP on mouse spermatozoa and their involvement in sperm-zona pellucida interactions. Biochemical and Biophysical Research Communications 318 148-155. (doi:10.1016/ j.bbrc.2004.04.006)

Calvert ME, Digilio LC, Herr JC \& Coonrod SA 2003 Oolemmal proteomics - identification of highly abundant heat shock proteins and molecular chaperones in the mature mouse egg and their localization on the plasma membrane. Reproductive Biology and Endocrinology 127. (doi:10.1186/1477-7827-1-27)

Cannon KS \& Cresswell P 2001 Quality control of transmembrane domain assembly in the tetraspanin CD82. EMBO Journal 20 2443-2453. (doi:10.1093/emboj/20.10.2443)

Cayli S, Jakab A, Ovari L, Delpiano E, Celik-Ozenci C, Sakkas D, Ward D \& Huszar G 2003 Biochemical markers of sperm function: male fertility and sperm selection for ICSI. Reproductive Biomedicine Online 7 462-468. (doi:10.1016/S1472-6483(10)61891-3)

Celik-Ozenci C, Catalanotti J, Jakab A, Aksu C, Ward D, Bray-Ward P, Demir R \& Huszar G 2003 Human sperm maintain their shape following decondensation and denaturation for fluorescent in situ hybridization: shape analysis and objective morphometry. Biology of Reproduction 69 1347-1355. (doi:10.1095/biolreprod.103.019596)

Chang MC 1951 Fertilizing capacity of spermatozoa deposited in the fallopian tubes. Nature 168 697-698. (doi:10.1038/168697b0)

Chen MS, Tung KS, Coonrod SA, Takahashi Y, Bigler D, Chang A, Yamashita Y, Kincade PW, Herr JC \& White JM 1999 Role of the integrinassociated protein CD9 in binding between sperm ADAM 2 and the egg integrin alpha6beta1: implication for murine fertilization. PNAS 96 11830-11835. (doi:10.1073/pnas.96.21.11830)

Cho C, Bunch DO, Faure JE, Goulding EH, Eddy EM, Primakoff P \& Myles DG 1998 Fertilization defects in sperm from mice lacking fertilin ß. Science 281 1857-1859. (doi:10.1126/science.281.5384.1857)

Choi I, Woo JM, Hong S, Jung YK, Kim DH \& Cho C 2003 Identification and characterization of ADAM32 with testis-predominant gene expression. Gene 304 151-162. (doi:10.1016/S0378-1119(02)01202-7)

Cornwall GA 2009 New insights into epididymal biology and function. Human Reproduction Update 15 213-227. (doi:10.1093/humupd/ dmn055)

Dix DJ, Allen JW, Collins BW, Mori C, Nakamura N, Poorman-Allen P, Goulding EH \& Eddy EM 1996 Targeted gene disruption of Hsp70-2 results in failed meiosis, germ cell apoptosis, and male infertility. PNAS 93 3264-3268. (doi:10.1073/pnas.93.8.3264)

Dun MD, Smith ND, Baker MA, Lin M, Aitken RJ \& Nixon B 2011 The chaperonin containing TCP1 complex (CCT/TRiC) is involved in mediating sperm-oocyte interaction. Journal of Biological Chemistry 286 36875-36887. (doi:10.1074/jbc.M110.188888)

Dun MD, Aitken RJ \& Nixon B 2012a The role of molecular chaperones in spermatogenesis and the post-testicular maturation of mammalian spermatozoa. Human Reproduction Update 18 420-435. (doi:10.1093/ humupd/dms009)

Dun MD, Anderson AL, Bromfield EG, Asquith KL, Emmett B, McLaughlin EA, Aitken RJ \& Nixon B 2012b Investigation of the expression and functional significance of the novel mouse sperm protein, a disintegrin and metalloprotease with thrombospondin type 1 motifs number 10 (ADAMTS10). International Journal of Andrology 35 572-589. (doi:10.1111/j.1365-2605.2011.01235.x)

Ecroyd H, Jones RC \& Aitken RJ 2003 Tyrosine phosphorylation of HSP-90 during mammalian sperm capacitation. Biology of Reproduction $\mathbf{6 9}$ 1801-1807. (doi:10.1095/biolreprod.103.017350)

Eddy EM 1999 Role of heat shock protein HSP70-2 in spermatogenesis. Reviews of Reproduction 4 23-30. (doi:10.1530/ror.0.0040023) 
Ellerman DA, Pei J, Gupta S, Snell WJ, Myles D \& Primakoff P 2009 Izumo is part of a multiprotein family whose members form large complexes on mammalian sperm. Molecular Reproduction and Development $\mathbf{7 6}$ 1188-1199. (doi:10.1002/mrd.21092)

Ellis J 1987 Proteins as molecular chaperones. Nature 328 378-379. (doi:10.1038/328378a0)

Ergur AR, Dokras A, Giraldo JL, Habana A, Kovanci E \& Huszar G 2002 Sperm maturity and treatment choice of in vitro fertilization (IVF) or intracytoplasmic sperm injection: diminished sperm $\mathrm{HspA} 2$ chaperone levels predict IVF failure. Fertility and Sterility 77 910-918. (doi:10.1016/ S0015-0282(02)03073-X)

Evans JP 2012 Sperm-egg interaction. Annual Review of Physiology 74 477-502. (doi:10.1146/annurev-physiol-020911-153339)

Feldman DE, Thulasiraman V, Ferreyra RG \& Frydman J 1999 Formation of the VHL-elongin BC tumor suppressor complex is mediated by the chaperonin TRiC. Molecular Cell 4 1051-1061. (doi:10.1016/S10972765(00)80233-6)

Frenette G \& Sullivan R 2001 Prostasome-like particles are involved in the transfer of P25b from the bovine epididymal fluid to the sperm surface. Molecular Reproduction and Development 59 115-121. (doi:10.1002/mrd.1013)

Gadella BM 2008 Sperm membrane physiology and relevance for fertilization. Animal Reproduction Science 107 229-236. (doi:10.1016/ j.anireprosci.2008.05.006)

Gadella BM \& Harrison RAP 2000 The capacitating agent bicarbonate induces protein kinase A-dependent changes in phospholipid bilayer behavior in the sperm plasma membrane. Development 127 2407-2420.

Gadella BM, Tsai P-S, Boerke A \& Brewis IA 2008 Sperm head membrane reorganisation during capacitation. International Journal of Developmental Biology 52 473-480. (doi:10.1387/ijdb.082583bg)

Guenther MG, Yu JJ, Kao GD, Yen TJ \& Lazar MA 2002 Assembly of the SMRThistone deacetylase 3 repression complex requires the TCP-1 ring complex. Genes and Development 16 3130-3135. (doi:10.1101/gad.1037502)

Han C, Park I, Lee B, Jin S, Choi H, Kwon JT, Kwon YI, Kimdo H, Park ZY \& Cho C 2011 Identification of heat shock protein 5, calnexin and integral membrane protein 2B as Adam7-interacting membrane proteins in mouse sperm. Journal of Cellular Physiology 226 1186-1195. (doi:10.1002/jcp.22444)

Harrison RAP, Ashworth PJC \& Miller NGA 1996 Bicarbonate/ $\mathrm{CO}_{2}$, an effector of capacitation, induces a rapid and reversible change in the lipid architecture of boar sperm plasma membranes. Molecular Reproduction and Development 45 378-391. (doi:10.1002/(SICI)10982795(199611)45:3 <378::AID-MRD16>3.0.CO;2-V)

Hartmann JF, Gwatkin RBL \& Hutchinson CF 1972 Early contact interactions between mammalian gametes in vitro: evidence that the vitellus influences adherence between sperm and zona pellucida. PNAS 69 2767-2769. (doi:10.1073/pnas.69.10.2767)

Heikkila JJ, Browder LM \& Genamu L 1986 Heat shock gene expression in animal embryonic systems. Canadian Journal of Genetics and Cytology 28 1093-1105.

Hendrick JP \& Hartl FU 1993 Molecular chaperone functions of heat-shock proteins. Annual Review of Biochemistry 62 349-384. (doi:10.1146/ annurev.bi.62.070193.002025)

Hermo L, Wright J, Oko R \& Morales CR 1991 Role of epithelial cells of the male excurrent duct system of the rat in the endocytosis or secretion of sulfated glycoprotein-2 (clusterin). Biology of Reproduction 44 1113-1131. (doi:10.1095/biolreprod44.6.1113)

Hess B, Saftig P, Hartmann D, Coenen R, Lullmann-Rauch R, Goebel HH, Evers M, von Figura K, D'Hooge R, Nagels G et al. 1996 Phenotype of arylsulfatase A-deficient mice: relationship to human metachromatic leukodystrophy. PNAS 93 14821-14826. (doi:10.1073/pnas.93.25.14821)

Huang T, Fleming AD \& Yanagimachi R 1981 Only acrosome-reacted spermatozoa can bind and penetrate into zona pellucida: a study using the guinea pig. Journal of Experimental Zoology 217 286-290. (doi:10.1002/jez.1402170215)

Huszar G, Vigue L \& Morshedi M 1992 Sperm creatine-phosphokinase $\mathrm{M}$-isoform ratios and fertilizing potential of men - a blinded study of 84 couples treated with in vitro fertilization. Fertility and Sterility 57 882-888.

Huszar G, Stone K, Dix D \& Vigue L 2000 Putative creatine kinase $\mathrm{M}$-isoform in human sperm is identifiedas the 70-kilodalton heat shock protein HspA2. Biology of Reproduction 63 925-932. (doi:10.1095/ biolreprod63.3.925)
Huszar G, Celik-Ozenci C, Cayli S, Zayaczki Z, Hansch E \& Vigue L 2003 Hyaluronic acid binding by human sperm indicates cellular maturity, viability, and unreacted acrosomal status. Fertility and Sterility 79 1616-1624. (doi:10.1016/S0015-0282(03)00402-3)

Huszar G, Ozkavukcu S, Jakab A, Celik-Ozenci C, Sati GL \& Cayli S 2006 Hyaluronic acid binding ability of human sperm reflects cellular maturity and fertilizing potential: selection of sperm for intracytoplasmic sperm injection. Current Opinion in Obstetrics \& Gynecology 18 260-267. (doi:10.1097/01.gco.0000193018.98061.2f)

Huszar G, Jakab A, Sakkas D, Ozenci CC, Cayli S, Delpiano E \& Ozkavukcu S 2007 Fertility testing and ICSI sperm selection by hyaluronic acid binding: clinical and genetic aspects. Reproductive Biomedicine Online 14 650-663. (doi:10.1016/S1472-6483(10)61060-7)

Ibrahim NM, Gilbert GR, Loseth KJ \& Crabo BG 2000 Correlation between clusterin-positive spermatozoa determined by flow cytometry in bull semen and fertility. Journal of Andrology 21 887-894.

Ikawa M, Wada I, Kominami K, Watanabe D, Toshimori K, Nishimune Y \& Okabe M 1997 The putative chaperone calmegin is required for sperm fertility. Nature 387 607-611. (doi:10.1038/42484)

Ikawa M, Nakanishi T, Yamada S, Wada I, Kominami K, Tanaka H, Nozaki M, Nishimune Y \& Okabe M 2001 Calmegin is required for fertilin $\alpha / \beta$ heterodimerization and sperm fertility. Developmental Biology 240 254-261. (doi:10.1006/dbio.2001.0462)

Ikawa M, Inoue N, Benham AM \& Okabe M 2010 Fertilization: a sperm's journey to and interaction with the oocyte. Journal of Clinical Investigation 120 984-994. (doi:10.1172/JCl41585)

Ikawa M, Tokuhiro K, Yamaguchi R, Benham AM, Tamura T, Wada I, Satouh Y, Inoue N \& Okabe M 2011 Calsperin is a testis-specific chaperone required for sperm fertility. Journal of Biological Chemistry 286 5639-5646. (doi:10.1074/jbc.M110.140152)

Inoue N, Ikawa M, Isotani A \& Okabe M 2005 The immunoglobulin superfamily protein Izumo is required for sperm to fuse with eggs. Nature 434 234-238. (doi:10.1038/nature03362)

Jahn R \& Grubmüller H 2002 Membrane fusion. Current Opinion in Cell Biology 14 488-495. (doi:10.1016/S0955-0674(02)00356-3)

Jin M, Fujiwara E, Kakiuchi Y, Okabe M, Satouh Y, Baba SA, Chiba K \& Hirohashi N 2011 Most fertilizing mouse spermatozoa begin their acrosome reaction before contact with the zona pellucida during in vitro fertilization. PNAS 108 4892-4896. (doi:10.1073/pnas.1018 202108)

Johnson MH, Eager D, Muggleton-Harris A \& Grave HM 1975 Mosaicism in organisation of concanavalin A receptors on surface membrane of mouse egg. Nature 257 321-322. (doi:10.1038/257321a0)

Kaji K, Oda S, Shikano T, Ohnuki T, Uematsu Y, Sakagami J, Tada N, Miyazaki S \& Kudo A 2000 The gamete fusion process is defective in eggs of Cd9-deficient mice. Nature Genetics 24 279-282. (doi:10.1038/73502)

Kawarsky SJ \& King WA 2001 Expression and localisation of heat shock protein 50 in cultured bovine oocytes and embryos. Zygote 9 39-50. (doi:10.1017/S0967199401001058)

Kim T, Oh J, Woo JM, Choi E, Im SH, Yoo YJ, Kim DH, Nishimura H \& Cho C 2006 Expression and relationship of male reproductive ADAMs in mouse. Biology of Reproduction 74 744-750. (doi:10.1095/biolreprod. 105.048892)

Kovanci E, Kovacs T, Moretti E, Vigue L, Bray-Ward P, Ward DC \& Huszar G 2001 FISH assessment of aneuploidy frequencies in mature and immature human spermatozoa classified by the absence or presence of cytoplasmic retention. Human Reproduction 16 1209-1217. (doi:10.1093/humrep/16.6.1209)

Krege JH, John SWM, Langenbach LL, Hodgin JB, Hagaman JR, Bachman ES, Jennette C, O'Brien DA \& Smithies O 1995 Male-female differences in fertility and blood pressure in ACE-deficient mice. Nature 375 146-148. (doi:10.1038/375146a0)

Lachance C, Fortier M, Thimon V, Sullivan R, Bailey JL \& Leclerc P 2010 Localization of Hsp60 and Grp78 in the human testis, epididymis and mature spermatozoa. International Journal of Andrology 33 33-44. (doi:10.1111/j.1365-2605.2008.00948.x)

Leclerc P, de Lamirande E \& Gagnon C 1996 Cyclic adenosine $3^{\prime}, 5^{\prime}$ monophosphate-dependent regulation of protein tyrosine phosphorylation in relation to human sperm capacitation and motility. Biology of Reproduction 55 684-692. (doi:10.1095/biolreprod55.3.684) 
Lefievre L, Conner SJ, Salpekar A, Olufowobi O, Ashton P, Pavlovic B, Lenton W, Afnan M, Brewis IA, Monk M et al. 2002 Four zona pellucida glycoproteins are expressed in the human. Human Reproduction 19 1580-1586. (doi:10.1093/humrep/deh301)

Le Naour F, Rubinstein E, Jasmin C, Prenant M \& Boucheix C 2000 Severely reduced female fertility in CD9-deficient mice. Science 287 319-321. (doi:10.1126/science.287.5451.319)

Lin Y-N, Roy A, Yan W, Burns KH \& Matzuk MM 2007 Loss of zona pellucida binding proteins in the acrosomal matrix disrupts acrosome biogenesis and sperm morphogenesis. Molecular and Cellular Biology 27 6794-6805. (doi:10.1128/MCB.01029-07)

Mamelak D \& Lingwood C 2001 The ATPase domain of hsp70 possesses a unique binding specificity for 3 '-sulfogalactolipids. Journal of Biological Chemistry 276 449-456. (doi:10.1074/jbc.M006732200)

Mayer MP \& Bukau B 2005 Hsp70 chaperones: cellular functions and molecular mechanism. Cellular and Molecular Life Sciences 62 670-684. (doi:10.1007/s00018-004-4464-6)

Meinhardt A, Parvinen M, Bacher M, Aumuller G, Hakovirta H, Yagi A \& Seitz J 1995 Expression of mitochondrial heat shock protein 60 in distinct cell types and defined stages of rat seminiferous epithelium. Biology of Reproduction 52 798-807. (doi:10.1095/biolreprod52.4.798)

Miller D, Brough S \& al-Harbi O 1992 Characterization and cellular distribution of human spermatozoal heat shock proteins. Human Reproduction 7 637-645.

Mitchell LA, Nixon B \& Aitken RJ 2007 Analysis of chaperone proteins associated with human spermatozoa during capacitation. Molecular Human Reproduction 13 605-613. (doi:10.1093/molehr/gam043)

Miyado K, Yamada G, Yamada S, Hasuwa H, Nakamura Y, Ryu F, Suzuki K, Kosai K, Inoue K, Ogura A et al. 2000 Requirement of CD9 on the egg plasma membrane for fertilization. Science 287 321-324. (doi:10.1126/ science.287.5451.321)

Mori C, Nakamura N, Dix DJ, Fujioka M, Nakagawa S, Shiota K \& Eddy EM 1997 Morphological analysis of germ cell apoptosis during postnatal testis development in normal and Hsp 70-2 knockout mice. Developmental Dynamics 208 125-136. (doi:10.1002/(SICl)1097-0177(199701)208:1 $<125:: A I D-A J A 12>3.0$. CO;2-5)

Munoz-Gotera RJ, Hernandez-Gonzalez EO, Mendoza-Hernandez G, Contreas RG \& Mujica A 2001 Exocytosis of a 60 kDa protein (Calreticulin) from activated hamster oocytes. Molecular Reproduction and Development 60 405-413. (doi:10.1002/mrd.1103)

Muro Y \& Okabe M 2011 Mechanisms of fertilization - a view from the study of gene-manipulated mice. Journal of Andrology 32 218-225. (doi:10.2164/jandrol.110.010900)

Naaby-Hansen S \& Herr JC 2010 Heat shock proteins on the human sperm surface. Journal of Reproductive Immunology 84 32-40. (doi:10.1016/ j.jri.2009.09.006)

Naaby-Hansen S, Diekman A, Shetty J, Flickinger CJ, Westbrook A \& Herr JC 2010 Identification of calcium-binding proteins associated with the human sperm plasma membrane. Reproductive Biology and Endocrinology 8 6. (doi:10.1186/1477-7827-8-6)

Nakanishi T, Ikawa M, Yamada S, Parvinen M, Baba T, Nishimune Y \& Okabe M 1999 Real-time observation of acrosomal dispersal from mouse sperm using GFP as a marker protein. FEBS Letters 449 277-283. (doi:10.1016/S0014-5793(99)00433-0)

Nasr-Esfahani MH, Razavi S \& Mardani M 2001 Relation between different human sperm nuclear maturity tests and in vitro fertilization. Journal of Assisted Reproduction and Genetics 18 219-225. (doi:10.1023/ A:1009412130417)

Nasr-Esfahani MH, Abbasi H, Mirhosseini Z, Ghasemi N, Razavi S, Tavalaei M, Tanhaei S, Demeh MR, Ghaedi K \& Zaman Soltani F 2010 Can altered expression of hspa2 in varicocele patients lead to abnormal spermatogenesis? International Journal of Fertility \& Sterility 4 104-113.

Neuer A, Spandorfer SD, Giraldo P, Dieterle S, Rosenwaks Z \& Witkin SS 2000 The role of heat shock proteins in reproduction. Human Reproduction Update 6 149-159. (doi:10.1093/humupd/6.2.149)

Nishimura H, Cho C, Branciforte DR, Myles DG \& Primakoff P 2001 Analysis of loss of adhesive function in sperm lacking cyritestin or fertilin ß. Developmental Biology 233 204-213. (doi:10.1006/dbio.2001.0166)

Nixon B, Asquith KL \& John Aitken R 2005 The role of molecular chaperones in mouse sperm-egg interactions. Molecular and Cellular Endocrinology 240 1-10. (doi:10.1016/j.mce.2005.06.004)
Nixon B, Bielanowicz A, McLaughlin EA, Tanphaichitr N, Ensslin MA \& Aitken RJ 2009 Composition and significance of detergent resistant membranes in mouse spermatozoa. Journal of Cellular Physiology $\mathbf{2 1 8}$ 122-134. (doi:10.1002/jcp.21575)

Nixon B, Mitchell LA, Anderson AL, McLaughlin EA, O'Bryan MK \& Aitken RJ 2011 Proteomic and functional analysis of human sperm detergent resistant membranes. Journal of Cellular Physiology 226 2651-2665. (doi:10.1002/jcp.22615)

Oh JS, Han C \& Cho C 2009 ADAM7 is associated with epididymosomes and integrated into sperm plasma membrane. Molecules and Cells $\mathbf{2 8}$ 441-446. (doi:10.1007/s10059-009-0140-x)

Ohsako S, Hayashi Y \& Bunick D 1994 Molecular cloning and sequencing of calnexin-t: an abundant male germ cell-specific calcium-binding protein of the endoplasmic reticulum. Journal of Biological Chemistry 269 14140-14148.

Ohsako S, Janulis L, Hayashi Y \& Bunick D 1998 Characterization of domains in mice of calnexin-t, a putative molecular chaperone required in sperm fertility, with use of glutathione S-transferase-fusion proteins. Biology of Reproduction 59 1214-1223. (doi:10.1095/biol reprod59.5.1214)

Onoda M \& Djakiew D 1990 Modulation of Sertoli cell secretory function by rat round spermatid protein(s). Molecular and Cellular Endocrinology 73 35-44. (doi:10.1016/0303-7207(90)90042-7)

Primakoff P, Hyatt H \& Tredick-Kline J 1987 Identification and purification of a sperm surface protein with a potential role in sperm-egg membrane fusion. Journal of Cell Biology 104 141-149. (doi:10.1083/ jcb.104.1.141)

Redgrove KA, Anderson AL, Dun MD, McLaughlin EA, O'Bryan MK, Aitken RJ \& Nixon B 2011 Involvement of multimeric protein complexes in mediating the capacitation-dependent binding of human spermatozoa to homologous zonae pellucidae. Developmental Biology 356 460-474. (doi:10.1016/j.ydbio.2011.05.674)

Reid AT, Redgrove K, Aitken RJ \& Nixon B 2011 Cellular mechanisms regulating sperm-zona pellucida interaction. Asian Journal of Andrology 13 88-96. (doi:10.1038/aja.2010.74)

Robaire B, Hinton BT \& Orgebin-Crist M 2006 The epididymis. In Knobil and Neill's Physiology of Reproduction, 3rd edn, pp 1071-1148. Eds JD Neill, TM Plant, DW Pfaff, JRG Challis, DM de Kretser, JS Richards \& PM Wassarman. St Louis, MO, USA: Academic Press.

Rubinstein E, Poindessous-Jazat V, Le Naour F, Billard M \& Boucheix C 1997 CD9, but not other tetraspans, associates with the beta1 integrin precursor. European Journal of Immunology 27 1919-1927.

Saez F, Frenette G \& Sullivan R 2003 Epididymosomes and prostasomes: their roles in posttesticular maturation of the sperm cells. Journal of Andrology 24 149-154.

Sali A, Glaeser R, Earnest T \& Baumeister W 2003 From words to literature in structural proteomics. Nature 422 216-225. (doi:10.1038/ nature01513)

Schägger H \& von Jagow G 1991 Blue native electrophoresis for isolation of membrane protein complexes in enzymatically active form. Analytical Biochemistry 199 223-231. (doi:10.1016/0003-2697 (91)90094-A)

Schägger H, Cramer WA \& von Jagow G 1994 Analysis of molecular masses and oligomeric states of protein complexes by blue native electrophoresis and isolation of membrane protein complexes by two-dimensional native electrophoresis. Analytical Biochemistry 217 220-230. (doi:10.1006/abio.1994.1112)

Søgaard M, Tani K, Ye RR, Geromanos S, Tempst P, Kirchhausen T, Rothman JE \& Söllner T 1994 A rab protein is required for the assembly of SNARE complexes in the docking of transport vesicles. Cell $\mathbf{7 8}$ 937-948. (doi:10.1016/0092-8674(94)90270-4)

Sørensen JB 2005 SNARE complexes prepare for membrane fusion. Trends in Neurosciences 28 453-455. (doi:10.1016/j.tins.2005.06.007)

Stein KK, Go JC, Lane WS, Primakoff P \& Myles DG 2006 Proteomic analysis of sperm regions that mediate sperm-egg interactions. Proteomics 6 3533-3543. (doi:10.1002/pmic.200500845)

Sullivan R, Saez F, Girouard J \& Frenette G 2005 Role of exosomes in sperm maturation during the transit along the male reproductive tract. Blood Cells, Molecules, and Diseases 35 1-10. (doi:10.1016/j.bcmd. 2005.03.005) 
Sullivan R, Frenette G \& Girouard J 2007 Epididymosomes are involved in the acquisition of new sperm proteins during epididymal transit. Asian Journal of Andrology 9 483-491. (doi:10.1111/j.1745-7262.2007. 00281.x)

Tomes CN, Michaut M, Blas GAD, Visconti PE, Matti U \& Mayorga LS 2002 SNARE complex assembly is required for human sperm acrosome reaction. Developmental Biology 243 326-338. (doi:10.1006/dbio. 2002.0567)

Topfer-Petersen E, Wagner A, Friedrich J, Petrunkina A, EkhlasiHundrieser M, Waberski D \& Drommer W 2002 Function of the mammalian oviductal sperm reservoir. Journal of Experimental Zoology 292 210-215. (doi:10.1002/jez.1157)

Tsai P-S, De Vries KJ, De Boer-Brouwer M, Garcia-Gil N, Van Gestel RA, Colenbrander B, Gadella BM \& Van Haeften T 2007 Syntaxin and VAMP association with lipid rafts depends on cholesterol depletion in capacitating sperm cells. Molecular Membrane Biology 24 313-324. (doi:10.1080/09687860701228692)

Tsai PS, Garcia-Gil N, van Haeften T \& Gadella BM 2010 How pig sperm prepares to fertilize: stable acrosome docking to the plasma membrane. PLOS ONE 5 e11204. (doi:10.1371/journal.pone.0011204)

Tsai P, Brewis IA, van Maaren J \& Gadella BM 2012 Involvement of complexin 2 in docking, locking and unlocking of different SNARE complexes during sperm capacitation and induced acrosomal exocytosis. PLoS ONE 7 e32603. (doi:10.1371/journal.pone.0032603)

Visconti PE \& Florman HM 2010 Mechanisms of sperm-egg interactions: between sugars and broken bonds. Science Signalling 3 pe35. (doi:10.1126/scisignal.3142pe35)

Visconti PE, Bailey JL, Moore GD, Pan D, Olds-Clarke P \& Kopf GS 1995 a Capacitation of mouse spermatozoa. 1. Correlation between the capacitation state and protein tyrosine phosphorylation. Development 121 1129-1137.

Visconti PE, Moore GD, Bailey JL, Leclerc P, Connors SA, Pan D, OldsClarke P \& Kopf GS 1995 b Capacitation of mouse spermatozoa. II. Protein tyrosine phosphorylation and capacitation are regulated by a cAMP-dependent pathway. Development 121 1139-1150.

Walsh A, Whelan D, Bielanowicz A, Skinner B, Aitken RJ, O'Bryan MK \& Nixon B 2008 Identification of the molecular chaperone, heat shock protein 1 (chaperonin 10), in the reproductive tract and in capacitating spermatozoa in the male mouse. Biology of Reproduction 78 983-993. (doi:10.1095/biolreprod.107.066860)

Wassarman PM, Chen J, Cohen N, Litscher E, Liu C, Qi H \& Williams Z 1999 Structure and function of the mammalian egg zona pellucida. Journal of Experimental Zoology. Part B, Molecular and Developmental Biology 285 251-258. (doi:10.1002/(SICl)1097-010X(19991015)285: $3<251::$ AID-JEZ8 > 3.0.CO;2-1)

Yamaguchi R, Yamagata K, Ikawa M, Moss SB \& Okabe M 2006 Aberrant distribution of ADAM3 in sperm from both angiotensin-converting enzyme (Ace)- and calmegin (Clgn)-deficient mice. Biology of Reproduction 75 760-766. (doi:10.1095/biolreprod.106.052977)

Yanagimachi R 1994 Fertility of mammalian spermatozoa: its development and relativity. Zygote 2 371-372. (doi:10.1017/S0967199400002240)

Yanagimachi R \& Phillips DM 1984 The status of acrosome caps of hamster spermatozoa immediately before fertilization in vivo. Gamete Research 9 1-19. (doi:10.1002/mrd.1120090102)

Yonezawa N, Kanai-Kitayama S, Kitayama T, Hamano A \& Nakano M 2012 Porcine zona pellucida glycoprotein ZP4 is responsible for the sperm-binding activity of the ZP3/ZP4 complex. Zygote 20 389-397. (doi:10.1017/S0967199411000608)

Zen K, Liu DQ, Li LM, Chen CXJ, Guo YL, Ha B, Chen X, Zhang CY \& Liu Y 2009 The heparan sulfate proteoglycan form of epithelial CD44v3 serves as a CD11b/CD18 counter-receptor during polymorphonuclear leukocyte transepithelial migration. Journal of Biological Chemistry 284 3768-3776. (doi:10.1074/jbc.M807805200)

Zuppini A, Groenendyk J, Cormack LA, Shore G, Opas M, Bleackley RC \& Michalak M 2002 Calnexin deficiency and endoplasmic reticulum stress-induced apoptosis. Biochemistry 41 2850-2858. (doi:10.1021/ bi015967+)

Received 14 August 2012

First decision 28 September 2012

Accepted 19 November 2012 